\title{
A ESCRITURA FEMININA NO CONTO SUL-RIO-GRANDENSE
}

\author{
Gilda Neves da Silva Bittencourt*
}

\begin{abstract}
RESUMO: This work discusses literary representation made by women writers of Southern Brazilian literature from 70 's and 80's in the XXth century. Through these texts, we try both to identify recurrent subject matters which express preoccupations inherent to feminine condition and to indicate some traces which show the existence of a somewhat different way of writing, as to revealing a rather particular sensibility in a women's perception.
\end{abstract}

PALAVRAS-CHAVE: Feminine condition. Identity. Southern brazilian literature. Female-written short stories in 70's and 80's.

O desenvolvimento de um tema como este implica a existência de dois pressupostos básicos: $1^{\circ}$ ) de que existe uma literatura escrita por mulheres, sobre mulheres, com uma temática voltada às questões do feminino e com uma dicção e um tom peculiares; $2^{\circ}$ ) de que, no conjunto da produção literária em prosa, a narrativa curta (conto/crônica) apresenta-se com características próprias, como manifestação de um gênero que obteve grande representatividade após a segunda metade do século XX em vários países latino-americanos, inclusive no Brasil. No Rio Grande do Sul, particularmente, esta participação do conto no conjunto da produção literária alcançou o seu momento mais importante na década de 70 e início dos anos 80 , revelando nomes que vieram a se destacar no cenário da literatura brasileira, como Caio Fernando Abreu, Moacyr Scliar, Josué Guimarães, Tânia Faillace e João Gilberto Noll.

Assim sendo, analisar a escritura feminina nos contos da literatura sul-rio-grandense significa conciliar, numa mesma abordagem, as duas questões apontadas acima.

A situação da literatura escrita por mulheres no Rio Grande do Sul não difere da que dominou no restante do Brasil e da América Latina, ou seja, a sua exclusão do cânone e a conseqüente marginalização da mulher como produtora de cultura. Produzida numa região tradicionalmente identificada com as atividades pastoris ligadas à criação de gado, que exigia força viril e resistência física, e por longo tempo palco de disputas fronteiriças em face de sua situação geográfica, a literatura no Rio Grande do Sul, desde o seu nascedouro no século XIX até boa parte do século XX, reproduziu um tipo de sociedade dominada pelo lado masculino, onde os valores priorizados eram a bravura, a força física e o ímpeto guerreiro.

Nesta sociedade pastoril e guerreira masculinizada, dominada pelo sistema patriarcal, a mulher era um ser quase insignificante, sem vida própria e sem chances de vencer as barreiras da vida doméstica a que estava condenada, contribuindo para isso a sua generalizada falta de instrução.

A literatura ajudou, no nível da representação artística, a reproduzir a mesma situação de inferioridade da mulher já que a desvalorização de suas atividades e a insignificância social impediam até mesmo a sua utilização como assunto literário. As personagens femininas na literatura rio-grandense, até o início do século XX, desempenhavam função subsidiária, gravitando em torno dos homens como meros objetos - de uso, de posse, de prazer. O seu papel, quando eventualmente destacado, era o de motivar as ações violentas e as disputas que terminavam em morte, confirmando, assim, a função demoníaca e destruidora, enraizada na cultura machista dominante naquela sociedade, que as relacionava, invariavelmente, ao mal e à tentação.

No âmbito da produção literária, a situação não é diferente, pois a presença das mulheres é também insignificante em relação à dos homens, reforçando a sua exclusão do cânone literário. As poucas escritoras mulheres do final do século XIX e início do XX, de um modo geral, internalizam a ideologia patriarcal, reforçando os valores considerados universais e naturais, onde predomina o vetor masculino. Assim, os modelos de elocução e o tratamento temático (sobretudo na poesia, que foi a forma literária mais freqüente nas escritoras desse período) vêm do universo dos homens, evidenciando, com isso, o endosso daqueles valores ideológicos dominantes.

Mais adiante, na década de 40, com o florescimento de um neo-simbolismo na literatura gaúcha, cujas ressonâncias mais conhecidas estão na poesia inicial de Mario Quintana, temos a participação de uma voz feminina na figura de Lila Ripoll, praticamente a primeira poeta a abordar a experiência feminina sob a ótica da mulher. No entanto, devido à própria natureza da estética simbolista, a sua poesia, de teor fortemente alusivo e sugestivo, acabou por esconder a verdadeira natureza dos sentimentos efetivamente experimentados pela poeta, já que eram expressos

\footnotetext{
* Gilda Neves da Silva Bittencourt é professora dos cursos de graduação e de pós-graduação do Instituto de Letras da Universidade Federal do Rio Grande do Sul, com atuação nas áreas de Teoria Literária e Literatura Comparada.
} 
por imagens etéreas, impalpáveis, que apontavam muito mais a um desejo de fugir ou então de encobrir e velar, sobretudo as manifestações relativas à sexualidade feminina. Assim, a elocução poética de Lila Ripoll, embora revele uma feminilidade latente, ainda se apresenta fortemente contida e envergonhada, não ousando se manifestar às claras.

O surgimento de escritoras que encararam mais aberta e profundamente a problemática da mulher, desvendando os seus desejos mais íntimos e trazendo à luz as inquietações e percepções do real típicas de uma visão feminina, aconteceu somente a partir dos anos 60, agora não mais com as poetas, mas com as ficcionistas.

O objetivo deste trabalho é focalizar algumas escritoras-mulheres que produziram narrativas curtas nos anos 70 e 80, no sentido de identificar temáticas recorrentes que expressam preocupações constantes na esfera do feminino, e também para indicar a existência de um modo de escrever diferenciado, revelador de uma sensibilidade e de uma percepção individualizadas.

Não se trata, porém, de discutir se existe ou não uma escritura feminina em oposição à masculina, nem se há uma essencialidade própria de cada gênero, mas sim de mostrar representações literárias construídas pelas mulheres, destacando os seus traços comuns e os procedimentos inerentes à visão feminina predominante, responsáveis pela construção de sua escritura.

A primeira escritora aqui focalizada é Tânia Faillace, que escreveu, ao longo dos anos 70 do nosso século, três livros de contos que se destacam justamente por tratarem a questão da feminilidade sob uma ótica renovada, trazendo à tona problemas ancestralmente reprimidos, relacionados, sobretudo, às condições de inferioridade e opressão da mulher. Serão focalizados aqui os dois primeiros, respectivamente, $O 35^{\circ}$ ano de Inês (1971) e Vinde a mim os pequeninos (1977).

No primeiro livro, $O 35^{\circ}$ ano de Inês, temos a investigação da alma feminina em três situações diferentes: a Inês da narrativa que dá nome ao livro é aquela mulher criada à luz da sociedade patriarcal e conformada com seu papel social de moça solteira, dedicada à mãe viúva, à irmãs e aos sobrinhos, e voltada aos afazeres do lar, relegando a um segundo plano os seus anseios pessoais e sua sexualidade. Até que, prestes a completar 35 anos, começa a tomar consciência de si mesma: sua feminilidade, até então reprimida, começa a aflorar com força, desestruturando-a em face dos sentimentos ambíguos de que se vê assaltada repentinamente; sente prazer com as novas sensações, mas ao mesmo tempo sofre, constrangida pelos preconceitos que a acompanharam até ali. Inês então se divide, passando a levar uma vida dupla: em casa, continua sendo a mulher calada e trabalhadora de sempre; na rua, tem amantes cada vez mais variados. Esta experiência, porém ao invés de perturbá-la ou humilhá-la, contribui para o seu amadurecimento, permitindo-lhe entender as fragilidades e carências dos homens. Doando-se aos amantes, procurando lhes proporcionar compreensão e alívio, ela tenta dar um sentido à sua vida vazia de sentimentos. No entanto, ao se ver acuada diante da ameaça de ser "desmascarada" perante a família, Inês opta pela saída definitiva do suicídio. Assim, a personagem vivencia os conflitos da mulher que, repartida entre os preconceitos arraigados e a afirmação da sua sexualidade, sucumbe aos primeiros e, pressionada pela estrutura patriarcal da família, é condenada a uma existência vazia. Sem condições de fazer frente a essas duas forças, ainda poderosas em nossa sociedade, só lhe resta o caminho da morte.

O outro conto do mesmo livro, "O trigo e o tempo da sega", trata de um assunto bem diferente: Antonieta, a personagem principal, é alguém que de repente se descobre velha, solitária e frágil, mas, ao invés de se deixar abater, mantém a consciência tranqüila de quem sempre procurou doar-se aos outros; a sua compreensão para com o próximo deriva de um sentimento de gratidão a Deus, cuja proteção lhe permitiu uma existência saudável e uma disposição para ajudar os que dela necessitavam. Por isso, sente que já cumprira o que a vida lhe havia exigido e chegara à velhice com a serenidade de quem está com a "mesa posta" e as "malas feitas", pronta para aguardar a sua última visita. Por essa razão, Antonieta fica profundamente abalada ao constatar que Ismênia, uma companheira de pensionato internada num hospital, apesar de estar apodrecendo aos poucos em cima da cama, já sem uma perna e tomada pela gangrena, agarra-se com todas as forças à vida, negando-se a morrer. Para o espírito sereno e altruísta de Antonieta, que tem a consciência plena de sua finitude, este apego da amiga a um corpo já em decomposição é algo completamente incompreensível e inaceitável.

Em "A Filha", o terceiro conto do livro, acompanhamos o processo de degeneração mental de uma personagem que rejeita a própria filha. O isolamento aqui se manifesta na sua forma mais radical - a alienação da loucura -, mas, tal como as personagens anteriores, ela tenta superar as dificuldades pela compreensão de si mesma e dos outros. Ao final da narrativa, ao aceitar a sua enfermidade como irremediável, a mulher transfere para a filha o direito à vida, como ser humano integral, que lhe fora sempre negado. Desta forma, mesmo imersa na alienação da loucura, a personagem demonstra uma percepção profunda de seu mundo psíquico em suas relações com a realidade exterior. Assim sendo, a visão da demência feminina recebe aqui um tratamento diferenciado daquele que tradicionalmente caracteriza as personagens loucas da literatura ocidental, onde o desequilíbrio emocional e psíquico as transforma em autômatos, seres destituídos de vontade ou de qualquer possibilidade de articulação que resgate sua 
humanidade, restando-lhe invariavelmente o caminho da histeria ou do suicídio como "rendição final ao domínio do irracional". ${ }^{i}$ A percepção lúcida da própria alienação e o resgate de sua relação com a filha fazem da personagem de Tânia um ser capaz de superar, por si só, as próprias dificuldades.

Nas três histórias de $O 35^{\circ}$ Ano de Inês, as personagens femininas dispõem de uma força interior especial. Todas elas possuem uma capacidade interna de resolver problemas, o que as coloca num plano superior aos demais e, embora estejam aparentemente conformadas ao seu papel social e, alguns casos, capitulem diante das imposições do sistema, desenvolvem comportamentos que normalmente não fazem parte dos padrões femininos aceitos pela sociedade patriarcal. Esta abordagem da questão feminina, esboçada nos contos iniciais, manifesta-se como uma superioridade espiritual e moral ainda não perfeitamente definida, mas que atribui à mulher uma condição diferenciada.

Alguns contos do livro de 1977, Vinde a mim os pequeninos, aprofundam essa problemática, criando situações mais concretas, no que tange à sexualidade, que invertem as funções dos gêneros usualmente aceitas, ou seja, ao homem se atribui a dominação, a iniciativa, a racionalidade, a independência, enquanto à mulher cabe a submissão, a dependência, a emotividade e, conseqüentemente, a inferioridade. Em "Retranca", uma das histórias do livro, um homem e uma mulher se encontram, num momento passageiro, e vivenciam uma relação fugaz e inconseqüente que satisfaz um desejo puramente carnal. Mas, enquanto para o homem a experiência é frustrante e infeliz, para a mulher é enriquecedora, já ela consegue encarar com tranqüilidade as dúvidas e os possíveis desencantos experimentados nessa relação. Isto lhe permite avaliar de forma madura e consciente o tipo de envolvimento que experimentara e a fugacidade do encontro. Nesse equilíbrio racional em aceitar os próprios conflitos como parte de sua natureza, ela se faz adulta e superior ao homem.

"Diálogo na cama", outro conto do mesmo livro, mostra uma mulher que procura liberar-se dos preconceitos e entregar-se ao sexo por puro prazer. São dela as iniciativas para o assédio sexual e o ângulo de visão sob o qual são mostradas as fantasias e os prazeres que experimenta. O homem significa para ela apenas um objeto de seu deleite, invertendo assim, radicalmente, a visão tradicional. No entanto, quando ele se afasta, ela fraqueja, sentindo-se vazia e solitária como se, no ato do amor, suas forças tivessem se esvaído e a autoconfiança abalada; para recuperar-se ela necessita de algum tempo até reencontrar a "rijeza" anterior.

O que fica implícito, através dessas narrativas de Tânia sobre a situação feminina, é uma afirmação da superioridade intrínseca da mulher e da necessidade da luta constante contra os preconceitos. Porém, os maiores avanços acontecem no plano intelectual, quando predomina a razão, enquanto no nível das emoções e principalmente no da sexualidade persistem as dificuldades, pois a relação unilateral acaba insatisfatória. Significa que, neste plano, é preciso haver um comprometimento mútuo no sentido de que mulher e homem se completem. Assim, a relação sexual pode conter, em alguns casos, uma capacidade regeneradora capaz de levar à superação de antigos tabus. É justamente isto o que acontece na outra narrativa sobre a mesma temática, "Racismo", em que a personagem resolve o preconceito racial, os traumas e as fantasias neuróticas de uma educação repressora, através de uma relação sexual verdadeiramente integral, onde a doação mútua permite que os dois amantes se bastem como homem e como mulher. Portanto, a perfeita integração no sexo é a fórmula para a mulher atingir a maturidade e a liberdade pessoal, e assim vencer os preconceitos, é esta a visão da feminilidade que se depreende das histórias de Tânia Faillace. Além disso, as narrativas de Tânia instauram um novo discurso onde a mulher é verdadeiramente o sujeito que fala de si e de seus problemas, sem as censuras e as simulações anteriores, um discurso que rompe antigos estereótipos e cria uma linguagem feminina que subverte as oposições de gênero enraizadas no sistema patriarcal.

A segunda autora de que nos ocupamos neste trabalho é Jane Tutikian, que já representa a geração de 80 da literatura sul-rio-grandense, focalizando de sua obra, particularmente, dois livros de contos: Batalha Naval (1981) e Pessoas (1987). A opção pela narrativa curta por parte da escritora acompanha e dá continuidade à tradição da geração de 70, que priorizou o conto em detrimento do romance, fazendo dele a forma literária mais praticada e divulgada.

A modernidade característica do tipo de literatura produzida nessa década, forjada nos anos duros da ditadura militar, permeia igualmente as narrativas de Jane Tutikian, na medida em que dizem respeito a relatos do quotidiano, com ambientação urbana e personagens quase anônimos, insignificantes, jovens vivenciando problemas inerentes ao seu tempo, em que as ilusões de um mundo cheio de paz, amor e liberdade já se tinham desfeito. Sua voz feminina, repleta de emotividade, dá um toque especial aos seus textos, deslocando o ângulo de visão e de percepção das coisas, propiciando uma análise diferenciada dos fenômenos ao privilegiar aspectos inusitados, imperceptíveis ou não valorizados pelo olhar masculino. Valendo-se de procedimentos usuais nas narrativas contemporâneas, como a descontinuidade, a elipse frasal ou a quebra da linearidade narrativa, a autora propõe uma representação peculiar que visa, essencialmente, ao desvendamento ou à investigação da feminilidade: tanto ao focalizar o confronto com o pólo masculino e a tradição patriarcal, como ao promover questionamentos sobre o papel da mulher como esposa, filha, mãe e amante; suas inquietações, suas dúvidas sobre o "estar no mundo" e sobre a construção da própria identidade. 
Ao lado disso, suas narrativas abordam freqüentemente uma experiência de aprendizagem, vivenciada, via de regra, por adolescentes que atravessam momentos de transição para uma nova fase da existência, como a passagem da infância para a adolescência, ou desta para a vida adulta. As personagens, ao percorrerem esse período traumático, vivem instantes de perturbação, de dúvida e perplexidade, após o quê saem enriquecidas e, sobretudo, mais maduras para enfrentar os desafios da nova fase que têm pela frente.

Os dois livros de contos que focalizaremos aqui contêm a mesma tonalidade e a atmosfera que perpassa a totalidade de sua obra, caracterizadas pelo intenso lirismo e pelo olhar inquiridor e curioso que busca retirar, de cada instante, um sentido mais profundo e um ensinamento para a vida, expressos sempre por uma fala de registro marcadamente feminino. Batalha Naval, sua primeira publicação, contém um elenco de dezoito narrativas curtas onde já se encontram delineadas as grandes linhas temáticas que seriam trabalhadas nas obras posteriores. Predominam ali os processos de análise introspectiva, em que as personagens experimentam momentos epifânicos de revelação de algo até então desconhecido ou ainda não perfeitamente identificados, mas capazes de alterar, momentaneamente para elas, o rumo dos acontecimentos. Um exemplo ilustrativo é o primeiro conto, "Um vento $\mathrm{S}$ 6.0", verdadeira confissão a um interlocutor desconhecido, relatando uma experiência efêmera de desejo, paixão e liberdade, vivida pela narradora num passado distante, quando se deparara com um navegador solitário que havia aportado na praia diante dela, perturbando-a profundamente, provocando-lhe sensações desconhecidas, reveladoras de seu outro "eu". Esse breve instante, vivido com intensidade apaixonada, deixara marcas indeléveis que o tempo não conseguira apagar, por ter sido, talvez, o seu grande momento de decisão sobre o destino que seguiria daí para frente.

Outros contos do mesmo livro procuram recuperar um passado, através de fragmentos da memória, na tentativa de dar sentido ou justificar determinadas experiências infantis marcantes, avaliando, com um olhar já distanciado no tempo, as repercussões que viriam posteriormente em termos de sentimentos ou vivências, como acontece em "Raízes mortas", em que o adulto recorda um momento de passagem da infância a adolescência, quando se afastara da casa paterna, deixando para trás não só a proteção e a segurança, mas principalmente o carinho e o amor dos pais. A ruptura que naquele momento parecia urgente e necessária é reavaliada pelo narrador adulto, com nostalgia e saudade, como uma perda de algo que a vida nunca mais the deu.

Há também narrativas centradas nas experiências da maternidade, nas suas várias etapas e em diferentes situações: em "O mistério da criação", é a mulher grávida que, em meio à náusea incômoda, reflete sobre sua prenhez e sobre o pequenino ser que se gera em suas entranhas; em "Cicatrizes", temos o relato de uma médica que acompanha a gestação e o momento do parto de sua paciente; em "Imersão", realidade e sonho se mesclam, produzindo imagens fantasmagóricas e estranhas, em que a personagem narradora dá a luz a si mesma, alternando os ângulos de visão da mãe e do recém-nascido; em "Entre mulheres", o centro das ações está num pequeno acontecimento que adquire um significado simbólico importante, por representar, numa relação mãe e filha, o instante do corte do "cordão umbelical".

O fato de encarar a velhice como a chegada da etapa derradeira da vida (também um momento de passagem) constitui, igualmente, uma das linhas temáticas dos contos de Batalha Naval ; em "Fila da morte", um homem tenso e angustiado devido à sua recente condição de aposentado, acha-se na expectativa de enfrentar, no dia seguinte, a fila do banco para receber sua pensão. É o momento de fazer um balanço de sua vida, avaliando suas perdas e ganhos; o peso da velhice é entristecedor e humilhante, fazendo-o sentir-se fraco e inútil. Em "Vida ao tempo", ao contrário, temos uma mulher que se recusa a envelhecer, assumindo os riscos de uma mudança radical em sua vida, porque interiormente ainda sente vibrar a juventude e o desejo de viver. O contraste das posturas do homem e da mulher, em que toca a esta última a visão mais positiva e madura, não se deixando abater como no caso do homem, confirma a perspectiva essencialmente feminina que assinalamos anteriormente nas narrativas de Tutikian.

O livro Pessoas, de 87, composto por quinze contos, retoma e amplia muitos aspectos abordados em Batalha Naval, enfatizando sempre as experiências existenciais da mulher. $\mathrm{O}$ ato da criação literária e seus envolvimentos no dia-a-dia da escritora, como um processo penoso de luta e de busca incessante, mas também de aprendizagem prazerosa, é um dos tópicos que Jane desenvolve com mais profundidade neste segundo livro de contos. Em Batalha Naval, a questão havia aparecido em um único texto, "No sétimo dia, talvez", em que a narradora, envolvida integralmente pelos cuidados com os filhos pequenos, não dispõe de tempo para se dedicar à personagem que teima em adquirir vida em sua mente. Pessoas aprofunda o tema, antes apenas tangenciado, abordando, por exemplo, em "Ciclo fértil", o conflito interior que se trava entre a mulher (e os apelos da vaidade feminina) e a escritora (permanentemente preocupada com problemas existenciais, sociais e metafísicos), acentuando a coexistência do confronto e da cumplicidade entre as duas.

As indagações sobre o "estar no mundo", as dúvidas e inquietações de quem tem a vida diante de si e quer fazer dela um constante processo de descoberta, mas também de quem se entristece com as desilusões e perdas que a mesma vida carrega, recebem um tratamento lírico todo especial em "Ponte das almas", "A um jovem equilibrista" e 
"Por perdas e danos". Por outro lado, inserindo esse desencanto num contexto típico da geração jovem dos anos 70, "Oh, I believe in yesterday" apresenta-se como uma crônica do quotidiano, motivadora de reflexões sombrias e nostálgicas, típicas da juventude de então, que vira ruir seus sonhos de construir um mundo feito de amor e paz. Diante do aniquilamento das esperanças, só resta o refúgio na força da poesia, nos versos que preservam o desejo de recuperar ou de manter sempre vivas a ingenuidade e as crenças de outrora, quando tudo era alegria e sonho, simbolizados, emblematicamente, nas canções dos Beatles.

Expandindo e dando continuidade à temática do primeiro livro, as experiências epifânicas de revelação, capazes de colorir com matizes diferenciados uma realidade até então nebulosa, obscura ou incompreensível, retornam nos contos "Decifração" e "Pessoas" (que dá título ao livro). Da mesma forma, a relação mãe e filho(a), analisada sob uma ótica feminina, como crise ou ruptura da ligação ingênita e natural, originada ainda no útero materno, está contemplada em "Verso e reverso" e "De anjo e de gente".

$\mathrm{O}$ vigor e o significado profundo que emanam dos contos de Jane Tutikian não podem ser desvinculados do seu processo de construção e de sua elaboração verbal; é a junção desses elementos que imprime a tonalidade própria de sua voz narrativa e individualiza a sua escritura artística. Como escritora atenta à literatura de seu tempo, sabe dosar harmonicamente os procedimentos desestruturantes da ficção contemporânea e a manutenção do equilíbrio interno da obra. Assim, é comum o início abrupto das ações, sem localizações espaciais ou temporais, ou sem apresentações formais das personagens; a linguagem, ainda que repleta de lirismo, é essencialmente sintética mesmo quando expressa estados interiores e sensações; o uso de recursos gráficos, comuns nos textos poéticos, intensificam o significado das palavras e permitem materializar, visualmente, o que elas estão dizendo. Efeito semelhante é obtido com a visualização gráficas das pausas da história, dos momentos vazios em que nada acontece, ou em que as personagens optam propositadamente em se manter caladas ou ausentes, através de trechos em branco ocupando o lugar das palavras.

Um outro traço estilístico marcante dos contos da autora é o uso da adversativa -mas- como fecho da frase, criando um efeito de suspensão, ou de impossibilidade de conclusão, e sugerindo, nessa "inconclusão suspensiva", uma impressão de perplexidade ou de dúvida diante de uma realidade indecifrável, ou um abertura para outras possibilidades de leituras, dando a entender que a realidade e os seres humanos são multifacetados, enigmáticos e surpreendentes.

Normalmente, as narrativas se constroem a partir de uma situação banal do quotidiano que sugere, à narradora feminina, reflexões variadas sobre o significado escondido por trás do aparentemente trivial, determinando um processo de autoconhecimento e identidade, ou então proporcionando um crescimento e um aprendizado em termos de experiência de vida. Este desvendamento se faz com idas e vindas do passado ao presente, como num jogo de alternância de planos, às vezes compondo um verdadeiro mosaico de fragmentos, cujo desenho só se completa ao final. Com isso, a composição ficcional dos contos se insere num padrão de experimentalismo próprio da literatura contemporânea, em que o conteúdo torna-se intrínseca e obrigatoriamente formal, em que, mais importante do que saber o quê dizer, é ter consciência do como dizer, fazendo do texto literário um jogo criativo que se fundem imaginação e linguagem.

A terceira escritora aqui enfocada é Patrícia Bins, nome dos mais conhecidos na literatura gaúcha contemporânea, sobretudo como ficcionista, autora de romances que começou a publicar no início dos anos 80. Os textos que escolhemos para analisar pertencem à sua primeira obra editada, O Assassinato dos Pombos (1982), reunindo contos e crônicas selecionados ( ou, conforme o subtítulo dado pela autora, "cronicontos"), já publicados no jornal Correio do Povo, de Porto Alegre, no período de 1976 a 1980.

O subtítulo é realmente bastante expressivo quanto à natureza do conjunto dos textos, na medida em que sugere, na união de conto e crônica, o caráter híbrido do livro. De fato, alguns textos apresentam-se como verdadeiras crônicas, recheadas de reflexões de teor lírico ou reminiscente, enquanto outros são relatos mais fixados em acontecimentos interligados e desenrolados numa sequiência temporal identificável.

Os textos de $O$ Assassinato dos Pombos são todos curtos, raramente ultrapassando as duas páginas (pois se tratam de textos originariamente escritos para jornal, onde há um limite estrito a ser observado), antecedidos invariavelmente por uma epígrafe inspirada em textos de poetas, escritores e escritoras, brasileiros ou estrangeiros. A natureza híbrida da composição faz com que os modos de narrar sejam também diversificados; assim, há narrativas em primeira pessoa, cuja voz se identifica com a cronista, outras vezes, essa voz é da personagem central da história; há também o caso em que o relato é feito em segunda pessoa, com uma narradora se dirigindo a alguém, como numa conversa informal; noutras ocasiões, há um narrador que não participa da história (e usa a terceira pessoa), mas centraliza a focalização dos fatos na personagem central do texto. Em determinados momentos, a autora vale-se de procedimentos mais sofisticados, como a alternância de narradores dentro do mesmo texto, mostrando um mesmo acontecimento ou situação sob ângulos diferenciados de visão e percepção. 
A dicção feminina atravessa todos os textos, seja pela predominância da narradora mulher, seja na centralização do interesse em temáticas ligadas às vivências e preocupações próprias das mulheres.

Não é nossa intenção estabelecer diferenças ou separações rígidas entre os contos e as crônicas de Patrícia Bins nesta obra, uma vez que a própria questão dos gêneros literários está sendo colocada em xeque na modernidade. A antiga separação dos gêneros herdada das Poéticas clássicas, e o próprio estatuto de Gênero têm a sua existência negada por algumas correntes do pensamento teórico contemporâneo da literatura. Preferimos, assim, tratar os textos como narrativas que se apresentam ora mais próximas daquilo que se costuma admitir como conto, ora mais impregnadas de lirismo, demonstrando sua afinidade com o feitio de crônica, tal como é conhecida em nossos dias. O importante aqui é ressaltar os modos como a escritura da autora se impregna de matizes femininos, tanto pela escolha dos temas, como do próprio tratamento lírico da linguagem.

Assim sendo, os textos "Feitiço" (p. 29), "Campo de mar azul" (p. 35) e "E agora, o que que eu faço?" (p. 39) são narrativas mais centradas em acontecimentos, onde é mais perceptível a presença de uma "história", no sentido de que alguma coisa é contada. No primeiro caso, a narradora-personagem relata uma série de fatos numa ligação cronológica e causal e apresentam nitidamente início, meio e fim - uma mulher pobre tem uma vida simples, enfrenta dificuldades financeiras, mas é feliz com o amante e os filhos até o dia em que descobre, no seu jardim, um objeto enfeitiçado (uma boneca de cera que reproduzia a sua figura, toda enrolada em fios de lã vermelha). A partir daí, o seu relacionamento com o companheiro começa a piorar, culminando com a separação e o retorno do amante à primeira mulher, que teria sido a responsável pelo feitiço. A narrativa se apresenta sob a forma de um relato que a narradora faz de uma experiência vivida a uma interlocutora invisível (talvez a própria autora), utilizando um registro coloquial de linguagem, porém impregnado de imagens metafóricas singelas que embelezam o texto.

Na segunda história, "Campo de mar azul", a narradora pertence à alta burguesia e vai procurar um operário para consertar o telhado de seu apartamento de cobertura. A informação que ela tem é de que o homem mora numa vila cujo nome é o título da história. Em razão do nome bonito, a mulher imagina ser um lugar agradável, com muita relva verde e cheiro de maresia, com girassóis e flores azuis espalhadas pelo caminho. Pouco a pouco, porém, a mulher vai percebendo a realidade cruel da vila: uma fileira de casas miseráveis, imersas na lama e na sujeira, e, ao chegar ao barraco procurado e deparar-se com a mulher do operário e seus vários filhos doentes, confinados num cubículo imundo e mal-cheiroso, leva um choque e sua primeira reação é correr ao armazém e à farmácia para abastecer a família pobre com alimentos e remédios, tentando com isso minimizar ou até mesmo compensar a sua alienação e seu distanciamento daquela realidade totalmente desconhecida para ela.

O terceiro texto, "E agora o que que eu faço?" é o mais extenso do livro; nele temos novamente uma narradora-personagem que conta a sua história, envolvendo um período de tempo que vai da infância até o momento em que tem o primeiro filho. A personagem é a mais velha de doze irmão, cujo pai é dono de um alambique no qual todos os filhos trabalham. A menina, subjugada desde cedo à dominação paterna, vai se tornando mulher, tem a sua primeira paixão, à qual se entrega plenamente, conseqüentemente, engravida, o namorado desaparece, o pai, enfurecido pela perda da virgindade da filha, espanca-a brutalmente e ela resolve fugir para a cidade grande. Lá encontra abrigo numa igreja, graças ao padre, mas depois que a criança nasce é obrigada a doar seu filho para um casal rico; quando tenta reavê-lo, não consegue mais.

A narrativa segue o mesmo tom lírico das demais, aqui sem o registro coloquial do primeiro texto, numa linguagem sobrecarregada de lirismo, como a expressar que a sensibilidade feminina está presente mesmo numa mulher simples e inculta.

Como se vê, as três narrativas possuem em comum o fato de que contarem uma história, com o desenvolvimento de um enredo, com personagens atuando em acontecimentos sucedidos num período temporal, mais ou menos extenso, configurando, assim, características próprias do gênero conto. Além disso, os três relatos focalizam situações ligadas, direta, ou indiretamente, às vivências femininas: a mulher que de repente passa da felicidade ao infortúnio, por obra de um feitiço no qual, em sua simplicidade, acredita piamente; a condição de alienação e distanciamento da mulher burguesa em relação às questões sociais; a condição de dependência e humilhação da mulher pobre, subjugada e oprimida desde a infância, e despojada de tudo, desde a dignidade até o próprio filho, e sem esperanças de vencer a exploração a que está condenada como mulher.

Ao lado desse tipo de texto, há outros em que não se configura nenhuma possibilidade de "enredo", ou de história, pois são puras reflexões ou digressões, por parte da narradora-mulher, motivadas por uma situação vivida ou um determinado fato presenciado. Um exemplo é "Freud explica" (p. 49), relato de um sonho em que a narradora chega a um restaurante acompanhada de um cavalo (como elemento onírico e simbólico da narrativa) e se dirige a uma mesa,. Uma vez instalada em seu lugar, sente-se deprimida, constrangida, fisicamente perturbada e acaba indo embora. Ou seja, nada acontece de fato, pois a quase totalidade da narrativa detém-se nas considerações íntimas da personagem, lutando contra a própria timidez. 
Outro exemplo que ilustra essa aproximação com a crônica é "Esperando Godot" (p. 55), onde a narradora, diante da janela aberta e, mais adiante, ao longo do jantar, reflete sobre o significado da peça de Samuel Becket que dá título ao texto, sobretudo no que tange à passagem do tempo e sua relação com mudança e permanência, e à impotência humana em alterar o rumo da história e da vida.

Em "Existências" (p. 69), a narradora expõe os pensamentos e inquietações que podem ocorrer a uma mulher burguesa, sem preocupações de ordem material e com a própria sobrevivência, ao acordar pela manhã. As reflexões giram em torno das questões de própria identidade e da possibilidade da existência de vários Eus, e da consciência da finitude do ser humano. Outro texto com características semelhantes é "A mesmice do mesmo" (p. 77), onde a narradora, ao reler, numa determinada crônica, uma afirmação sobre a intensidade de viver, passa a fazer uma série de considerações nostálgicas, em que lamenta haver perdido a sensibilidade para sentir, com maior intensidade, as pessoas e as coisas ao seu redor; com isso, sente-se esvaziada, vivendo num marasmo, sem coragem de superá-lo. Em "Uma espécie de silêncio" (p. 123), a crônica flagra um momento de atrito entre um casal durante uma viagem de carro e, na visão lírica da narradora, ela contrasta a paisagem límpida, clara e iluminada dos campos, das casas, dos animais e das flores que vê se desenrolando sucessivamente no exterior, com a paisagem interior, feroz e ressentida do homem e dela própria.

Em todos os textos, mesmo naqueles mais próximos do conto, predomina o lirismo da autora, que sempre procura penetrar mais a fundo no significado das coisas que aparecem à superfície, com digressões sobre a existência dos seres e o estar no mundo. A perspectiva com que as narradoras abordam a questão feminina prioriza, via de regra, as dificuldades de relacionamento homem-mulher, ou as barreiras de uma educação repressora que segrega ou oprime a mulher, ou então focaliza a súbita conscientização, por parte de uma burguesa alienada e fútil, de uma questão de ordem social. O tratamento da temática feminina na sua generalidade, no entanto, aponta muito mais à denúncia ou a simples exposição do problema do que a uma proposta de transformação. O final das narrativas não propõe alternativas para superar as dificuldades encontradas pelas mulheres, sobretudo nas classes mais desfavorecidas, e reafirma a sua discriminação e opressão dentro de um sistema ainda dominada pelo lado masculino. Por outro lado, os textos em que a mulher alienada experimenta um instante de revelação, em que toma consciência de realidades diversas da sua, acabam evidenciando a efemeridade desse momento, já que as personagens retornam à anterior alienação e aos valores anteriormente cultivados, ou então as narradoras permanecem insatisfeitas ou sentem-se culpadas, sem forças para modificar as coisas.

As três escritoras aqui analisadas exemplificam modos diferenciados de tratar a questão feminina, embora encontremos nelas algumas afinidades. Assim, temos uma visão libertadora que subverte e dá novo sentido aos padrões da ideologia patriarcal, destacando a superioridade da mulher sobre o homem, manifestada nos contos de Tânia Faillace. Em Jane Tutikian, vemos igualmente a valorização da mulher, sobretudo em sua capacidade de resolver por si mesma os problemas e os desafios que lhe são impostos, num âmbito das vivências mais amplas e não apenas nas relações homem/mulher. Em Patrícia Bins, nos textos analisados, a problemática feminina é apresentada ora sob um ângulo de mulheres socialmente desfavorecidas, ora sob a ótica de mulheres da burguesia, porém sem que haja ali uma proposta renovadora que transforme verdadeiramente a situação de precariedade apontada. Por outro lado, há em comum entre as três autoras o lirismo que impregna as suas linguagens e perpassa a totalidade dos textos, evidenciando uma sensibilidade e um olhar subjetivo "desviado" que analisa e busca insistentemente o sentido oculto que subjaz abaixo do visível, descobrindo a beleza das coisas pequenas e quase insignificantes.

As três autoras demonstram um mesmo pendor ao desvendamento interior, preocupando-se com questões que usualmente não entram no campo de visão do olhar masculino, voltado às vezes muito mais ao porquê dos acontecimentos, do que ao como estes mesmos acontecimentos são recebidos e analisados do interior dos seres humanos. A percepção feminina, talvez mais atenta aos detalhes, mais sensível às transformações ou às agressividades do mundo, expressa-se com maior plenitude, fazendo com que a escritura feminina seja imediatamente reconhecida em sua diferença.

Notas:

${ }_{1}^{1}$ Cf. SCHMIDT, Rita T. Apresentação. In: Organon - A mulher e a literatura. Vol. 16, nº 16, 1989. POA: UFRGS, p. 11.

${ }^{2}$ SCHMIDT, Rita T. Mulher e Literatura. In: SCHULER, Donaldo, org. Mulher em Prosa e Verso. Porto Alegre: Movimento, 1988 , p. 130. 